\title{
Searching for Human Connectedness During COVID-19
}

\author{
Margaret McNairy, MD, Msc ${ }^{1,2}$, Brooke Bullington, $B A^{2}$, and Kimberly Bloom-Feshbach, \\ $M D^{l}$
}

'Section of Hospital Medicine, Division of General Internal Medicine, Weill Cornell Medicine New York, NY, USA; ${ }^{2}$ Center for Global Health, Weill Cornell Medicine New York, NY, USA.

The COVID-19 pandemic has fundamentally transformed doctor-patient communication, stripping away moments of connection that define the humanism of medicine. The barrier of isolation has impacted patients and patient care, and has also affected the experience of the physician. Though in-person connection is impossible to replicate digitally, technology has restored some sense of togetherness.

$\mathrm{J}$ Gen Intern Med 35(10):3043-4

DOI: $10.1007 / \mathrm{s} 11606-020-06082-9$

(c) Society of General Internal Medicine 2020

I am in my eighth week of COVID care as an internal medicine physician in New York City. Despite being surrounded by patients and my colleagues, the days have become oddly lonely and disorienting as I prep to see my next patient. I follow my drill: don scrubs, a tight-fitting N95 mask, and plastic goggles. I then slide into my second protective layer - a large yellow paper gown, pale blue hairnet, latex gloves, and an awkward plastic face shield. I am now ready to enter my patient's room and introduce myself. He is 47 years old, a beloved father, and breathing too fast. I can barely see through the two layers of foggy plastic over my eyes, but even then, I can see he is scared. My week-old mask is grimy and smells. I am hot and light-headed wrapped up like this. Senses blunted by all the PPE, my mind wanders. I feel acutely alone, disconnected, in my thoughts and body, in almost a futuristic sense. Maybe this is what it is like for astronauts floating around in their moon suits when in space, trying to move forward.

I introduce myself by literally yelling "hello" through the layers of protection so that my new patient can hear me over the humming of oxygen tubes and cardiac monitors. "I'm Dr. McNairy and I'm going to be your doctor today. You can call me Molly." Sometimes they nod, sometimes they cannot hear me above the din and I scream louder through my suffocating layers. I laugh at myself. It feels absurd to be screaming introductions but the patient cannot tell through the layers of

Received May 10, 2020

Accepted July 27, 2020

Published online August 10, 2020 plastic. The physical exam is remarkably brief and centers on checking the monitors for the most important prognostic data for COVID-19 - the heart rate, respiratory rate, and oxygen level. I'm supposed to stand six feet away while talking to the patient but it is hard not to resume old habits. I put a gloved hand on his shoulder, but the PPE seems to silence the reassurance I'm trying to express. I hurriedly inform him that he has tested positive, and while neither of us are surprised, it comes with a wave of fear and worry for us both. Will he get sicker? What is his prognosis? Will he survive intubation? And if he does survive, will it be with a breathing tube in his neck and what will he think of his new life?

Before COVID-19, we would typically round as a team. I would often sit on the patient's bed, with students and residents surrounding the patient in the center. We take pride in talking with the patient for as long as it takes - talking is the connective tissue of the patient-doctor relationship. We take time to answer and re-answer questions, tell a lame joke to bring some laughter into their treatment plan. We perform an exacting and meticulous physical exam. There are countless subtle opportunities for human connection-a handshake, smile, fist bump, a tissue offered, even a hug now and then. We circle back to the bedside whenever a question arises or new result returns, checking in and providing updates and emotional support.

Now in the time of COVID-19, a patient sees one doctor once a day to minimize infectious risks and the use of PPE. The patients have no visitors. We prioritize that the most experienced doctor sees the sickest patients and divide the patients across our team. There are no traditional rounds and we re-convene in hallways to discuss those patients we did not see. The patient's medical history and chart is reviewed prior to entering the room. The medical plan is unsatisfyingly limited to supportive care without much nuance: increase the oxygen as needed to keep saturation levels greater than $90 \%$; call for intubation if the patient worsens.

Our hospital requires we confirm a patient's "code status" immediately upon admission. Normally, these conversations are long and personalized. Today, they are done in minutes by doctors hidden in PPE. I only allot several minutes for questions, clarification, and connection. Soon, I will pull off (or "doff" as the have taught me to say) my PPE and rush to redress for the next patient. The process repeats. Doffing my layers of protection, I feel like a shell of my former self. 
At the end of rounds, our team disbands to call patient families for updates. There are so many questions from families who are not allowed to visit their loved ones. I feel their desire for human connection, reassurance, and hope from across the phone. In too many cases, we do not have the answers. I leave many shifts feeling angry that I cannot fully communicate with my patients and at the same time, they cannot communicate with their families.

One night several weeks ago, I finally respond to the dozens of texts from friends and colleagues asking how they can help. I reply that it would be wonderful if we could humanize the COVID-19 experience, and maybe tablets could help the hospital experience be less. Within $48 \mathrm{~h}$, donors send close to a thousand iPads, and we immediately form a taskforce to operationalize their use, connecting them to patients across the emergency rooms and medical floors.

Over the past few weeks, tablets have become a portal for human connection. Before COVID-19, I would flinch when new technology was introduced. Each technological rollout seemed to distract me from patients - more electronic medical documentation and unwieldy discharge procedures. Now, technology was restoring our ability to connect.

The primary use of the tablets has been to connect patients to their loved ones who cannot visit them in the hospital. Conversations are life-giving and range from uneventful chit-chat to intimate conversations among critically ill patients and their families. In a recent example, a feisty 90-year-old patient with a career in science FaceTimed her son, who was far away but desperately wanted to see his mom. She had never used an iPad and was irritable asking the staff why they insisted she try it. But when she saw her son's face, they both beamed. They bantered for several minutes, and then she abruptly said "I talk with you and now I am done, goodbye" and pushed the red disconnect button. The room filled with laughter - the commodity in shorter supply than PPE. In another example, a newly married, young man was becoming sicker. We connected him to his wife just before he was to be intubated to rest his lungs. There were not many words as we all felt our eyes swell with tears and left them to speak privately. My most tender moment was connecting a medical colleague at another hospital with her elderly grandmother. The grandmother's health was deteriorating, and we were no longer able to supply her with enough oxygen to feed her body. She was adamant about not wanting to be on a ventilator. The moment had come to shift our efforts from treatment to comfort. I found a tablet, dialed her granddaughter's number and put her face beside her beloved babushka. They gasped "I-love-you's" and cherished phrases in what would be the last moments of lucid conversation.
Our practice now includes bringing each of my patients a tablet, which I use to check in with them throughout the day. They get to see my unmasked face as we talk thoroughly about the prognosis and care plan. They give me real-time information about their health status by showing me their oxygen saturations. Other times, we just talk about the weather or which of our favorite restaurants will be open after all of this is over. No matter the subject matter, these calls make me feel like a doctor again. They enhance my relationships with patients and provide a semblance of the missing in-person human connection.

We also use the tablets to have sensitive discussions with patients and their families about critical care decisions and goals of care. Patients often want their health care proxy and families to help them decide what to do should they become sicker. The discussions are complex, emotional, and pivot on the ability to communicate values. Faces and body language speak volumes. We are able to talk about what matters most, human to human.

Tablets by no means replace human touch. Yet in the alternate universe that has become the day-to-day practice of medicine during COVID-19, they have restored some of the humanism otherwise lost. We find ourselves giddy to show the patient how to connect with their loved ones and feel relief when relatives answer and the pixels converge into human faces. The tone in our offices where doctors huddle between rounds for coffee and writing notes is not without darker moments, but there is now room for some small talk and laughter. We find ourselves sharing the human stories of our patients and their families. It does not wipe away the bleakness and exhaustion of the COVID-19 shifts, but it does feel like a bit of relief poking through the gray.

Acknowledgements: We would like to thank Devon Spurgeon and other donors for procuring tablets and Khalid Haynes, Faudia Pasha for programming the tablets.

Corresponding Author: Brooke Bullington, BA; Center for Global Health, Weill Cornell Medicine New York, NY, USA (e-mail: bbullington@unc.edu).

Publisher's Note: Springer Nature remains neutral with regard to jurisdictional claims in published maps and institutional affiliations. 